\title{
Mining
}

\section{Recovery of pellet feed from tailings dams}

http://dx.doi.org/10.1590/0370-44672018720088

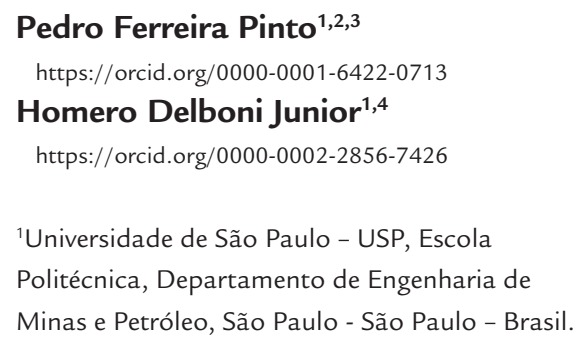

${ }^{2}$ Vale - Diretoria de Programação Integrada, Nova Lima - Minas Gerais - Brasil.

E-mails: ${ }^{3}$ pedro.ferreira.pinto@vale.com, phfp@uol.com.br, ${ }^{4}$ hdelboni@usp.br

\begin{abstract}
Not long ago, certain iron ore processing plants in Brazil were unable to efficiently recover iron ore fines and, as a result, operated only with high grade iron ore. For this reason, material stored in some iron ore tailings dams have considerable amounts of iron content with a potential to produce pellet feed fines through a concentration process. This study presents the results of magnetic concentration tests carried out on samples from four iron ore tailings dams located in Minas Gerais, named as A, B, C and $\mathrm{D}$. The average iron content is $54 \%$ for A dam, $36 \%$ for B dam, $49 \%$ for $\mathrm{C}$ dam, and $58 \%$ for $\mathrm{D}$ dam. This material had a significant amount of ultra-fine particles, with more than $50 \%$ below $0.045 \mathrm{~mm}$ for all dams, particularly the A and D dams, which present more than $80 \%$ of the below $0.045 \mathrm{~mm}$ on average. Magnetic concentration tests were conducted on bench and pilot scales. The resulting concentrates showed the following average iron content: $66 \%$ for dam A, $63 \%$ for dam B, and $67 \%$ for dams $\mathrm{C}$ and $\mathrm{D}$, with a mass recovery of $42 \%$ for dam A, $38 \%$ for dam B, $75 \%$ for dam $\mathrm{C}$, and $63 \%$ for dam $\mathrm{D}$. These results confirm the potential for pellet feed production from tailings dams through magnetic concentration.
\end{abstract}

keywords: tailings dam; pellet feed; magnetic concentration; iron ore.

\section{Introduction}

The environmental aspects of tailings dams are a substantial issue from the standpoint of ore production sustainability, especially in the case of idled dams, which cannot receive more tailings, but represent a permanent environmental impact and geotechnical risk; hence their need to be continuously monitored.

Not long ago, certain iron ore processing plants in Brazil were unable to efficiently recover iron ore fines and, as a result, operated only with high grade and material that generates coarse products. For this reason, material stored in some iron ore tailings dams have considerable amounts of iron content, with a potential to produce pellet feed fines through a concentration process. In this context, a series of characterization and recovery studies of the fines deposited in tailings dams is being developed. Ferrante (2014) demonstrates the economic viability of the production of pellet feed fines from an idled dam.

The recovery of ore fines from tailings dams usually poses a number of challenges, such as material heterogeneity, throughput fluctuations due to difficulty in recovering and handling the tailings, and the presence of contaminants such as natural sediment, sand, and organic materials. Ribeiro and Ribeiro (2015) show the problems in magnetic concentration due to blockage in the matrix by coarse particles and organic materials.

Magnetic concentration has been considered the most appropriate process route to cope with the above challenges and concentrate fines from tailings dams. This concentration process is less sensitive to variations in the feed and more efficient when processing ultra-fine particles (below $0.01 \mathrm{~mm}$ ) than other options for concentrating iron fines, like reverse flotation. Even reverse flotation is not highly efficient in processing ultra-fines particles. Pena and Marques (2011), Ribeiro et al (2017) and Sales (2012) demonstrate the viability in using magnetic concentration for the recovery of iron ore fine and ultra-fine particles in the tails.

This article presents the results of magnetic concentration tests carried out on samples from four iron ore tailings dams located in Minas Gerais, named as A, B, C and D. 


\section{Materials and method}

The tests were conducted on samples taken from probing holes from dams A, $\mathrm{B}$ and $\mathrm{C}$. In the case of tailings dam D, samples were collected by means of a dredge and other mechanical equipment, as it was not feasible to sample through probing holes. Each sample taken from the dams was submitted to particle size determination and chemical analysis by $\mathrm{X}$ ray fluorescence for initial characterization. The resulting characterization provided an overview of the fines disposed in the tailings dams and input for the definition of magnetic concentration test parameters.

Magnetic concentration tests were conducted on bench and pilot scale. Equipment L4 from Vale's Technological Research Center was used in the bench tests. This apparatus consists of a fixed plate box between two induction magnetic yokes. It is possible to obtain a higher than 1.5 T magnetic field in the plate box, like in industrial operations. In order to simulate the mass recovery and concentrate grade of an industrial operation, a reduced magnetic field ranging from 0.1 $\mathrm{T}$ to $0.8 \mathrm{~T}$ is used. The test consists of feeding dry samples into the magnetized plate box along with water to wash off nonmagnetic material. The magnetic

\begin{tabular}{|c|c|c|c|c|c|}
\hline \multirow[b]{2}{*}{ Tailing Dam } & \multicolumn{2}{|c|}{ Bench tests } & \multicolumn{3}{|c|}{ Pilot Tests } \\
\hline & $\begin{array}{l}\text { Magnetic } \\
\text { Fild }(T)\end{array}$ & Gap (mm) & $\begin{array}{l}\text { Magnetic } \\
\text { Fild }(T)\end{array}$ & Gap (mm) & $\begin{array}{c}\text { Rotation } \\
\text { (RPM) }\end{array}$ \\
\hline Dam A & 0.6 & 1.0 & 1.1 & 1.5 & 5.0 \\
\hline Dam B & 0.7 & 2.5 & 1.1 & 1.5 & 5.0 \\
\hline Dam C (10'step) & 0.1 & 1.5 & $x$ & $x$ & $x$ \\
\hline Dam C (20 Step) & 0.4 & 1.5 & $x$ & $x$ & $x$ \\
\hline Dam C ( $3^{0}$ Step) & 0.4 & 1.5 & $x$ & $x$ & $x$ \\
\hline Dam D & $X$ & $X$ & 1.0 & 1.5 & 5.0 \\
\hline
\end{tabular}

field is then turned off and the magnetic material is washed off the plate. Primary variables are the magnetic field and the plate box gap. Bench tests were carried out on each probing hole sample so that the test data show the average, maximum and minimum results.

Vale's Technological Research Center's Minimag, supplier by Gaustec Minerals Technology, apparatus was used in pilot tests. This equipment features one rotor and a reduced diameter and replicates the Wet High Intensity Magnetic Separator (WHIMS) industrial operation. The Minimag plate boxes have the same height as a full-scale industrial machine, so as to represent the time during which particles remain under the effect of a magnetic field in a pilot scale. Paula (2014) compared results obtained in a series of pilot tests done in the Minimag with industrial operations of magnetic concentration confirming the correlation between pilot and industrial scales is straightforward. Variations of the industrial process parameters, such as rotation, proportion of solids in the feed, magnetic field and plate box gap, can be simulated in this pilot apparatus. Pilot tests were carried out on a group of samples under constant test conditions. The group of samples were done in function of the location of the samples in the dam.

The pilot test is started with the activation of the electric current in the coils of the concentrator, for induction of the magnetic field. The magnetic field is measured inside the matrices using a Gaussmeter. The concentrator was fed with pulp having a density of $1.4 \mathrm{t} / \mathrm{m}^{3}$, prepared in a $250 \mathrm{~L}$ stirring tank. The feed rate of the tests was kept constant at $0.7 \mathrm{~m}^{3} / \mathrm{h}$ measured by a flowmeter installed in the line and controlled by the variation of the pump rotation. The test has the duration of five minutes, with the total collection of the flows.

Bench and pilot tests were conducted on samples from the A and B dams. Samples from the $\mathrm{C}$ dam were submitted only to bench tests, which were carried out in three stages, with the tailings of one stage being the feed for the next stage. In the case of the $\mathrm{D}$ dam, only the pilot test was carried out, due to the lack of probing hole samples.

Table 1 shows the bench and pilot tests conducted on samples from each tailings dam.

Table 1

Pilot and bench

magnetic concentration tests.

\section{Results and discussions}

Table 2 shows the size and chemical analysis results for samples from four tailings dams.

Table 2

Size and chemical and analyses.

\begin{tabular}{c|c|c|c|c|c|c|c|c|c}
\multirow{2}{*}{ Tailing Dam } & \multicolumn{3}{|c|}{ Fe (\%) } & \multicolumn{3}{c|}{ SiO $_{2}+\mathrm{Al}_{2} \mathbf{O}_{3}(\%)$} & \multicolumn{3}{c}{$<0.045 m m(\%)$} \\
\cline { 2 - 11 } & Minimum & Average & Maximum & Minimum & Average & Maximum & Minimum & Average & Maximum \\
\hline Dam A & 47.7 & 53.8 & 56.4 & 13.3 & 16.6 & 23.5 & 71.5 & 80.0 & 86.2 \\
\hline Dam B & 33.0 & 36.0 & 39.3 & 38.8 & 43.9 & 48.4 & 59.5 & 67.1 & 81.4 \\
\hline Dam C & 37.0 & 48.6 & 60.8 & 10.2 & 24.1 & 39.0 & 29.7 & 58.8 & 100.0 \\
\hline Dam D & 55.6 & 58.0 & 60.0 & 11.6 & 15.1 & 17.7 & 76.6 & 83.7 & 93.4 \\
\hline
\end{tabular}


Tailings from the A and D dams feature the highest iron content, at $58.0 \%$ and $53.8 \%$, respectively, on average. These dams contain really fine material, with more than $80 \%$ below $0.045 \mathrm{~mm}$ on average. The $\mathrm{C}$ dam's tailings were very heterogeneous in both chemistry and size. In some areas, the material was coarse and iron-rich, with less than $40 \%$ below $0.045 \mathrm{~mm}$ and higher than $55 \% \mathrm{Fe}$ content. In other areas, the material was fine and poor, with almost $100 \%$ below $0.045 \mathrm{~mm}$ and lower than $45 \%$ Fe content. The B dam had the lowest grade material, but it was considerably homogeneous and did not contain a large amount of fines.

Table 3 shows the bench test results for tailings from the A, B and C dams, whereas Figures 1 to 3 show pilot test results for the $A, B$ and $D$ dams, respectively.

Table 3

Bench test results

\begin{tabular}{|c|c|c|c|c|c|c|c|c|c|c|c|c|}
\hline \multirow{2}{*}{$\begin{array}{l}\text { Tailing } \\
\text { Dam }\end{array}$} & \multicolumn{3}{|c|}{ Concentrate - Fe (\%) } & \multicolumn{3}{|c|}{ Concentrate $-\mathrm{SiO}_{2}+\mathrm{Al}_{2} \mathrm{O}_{3}(\%)$} & \multicolumn{3}{|c|}{ Tailing - Fe (\%) } & \multicolumn{3}{|c|}{ Mass Recovery (\%) } \\
\hline & Minimum & Average & Maximum & Minimum & Average & Maximum & Minimum & Average & Maximum & Minimum & Average & Maximum \\
\hline A & 63.6 & 65.6 & 66.7 & 2.5 & 3.3 & 5.3 & 33.2 & 37.9 & 43.6 & 49.0 & 57.2 & 64.0 \\
\hline B & 64.3 & 64.9 & 65.5 & 4.1 & 4.6 & 5.2 & 23.5 & 24.8 & 26.1 & 23.2 & 26.8 & 31.6 \\
\hline $\begin{array}{c}\mathrm{C} \\
\left(1^{0} \text { Step) }\right. \\
\end{array}$ & 67.9 & 68.6 & 69.2 & 1.0 & 1.2 & 1.7 & 48.0 & 51.2 & 55.7 & 22.0 & 32.5 & 51.4 \\
\hline $\begin{array}{c}\mathrm{C} \\
\left(2^{0} \text { Step }\right) \\
\end{array}$ & 67.4 & 67.9 & 68.7 & 1.1 & 1.6 & 2.0 & 27.9 & 31.8 & 35.2 & 58.3 & 68.5 & 81.8 \\
\hline $\begin{array}{c}\mathrm{C} \\
\left(3^{0} \text { Step) }\right.\end{array}$ & 67.0 & 67.5 & 68.4 & 1.3 & 2.0 & 2.5 & 20.2 & 22.9 & 25.6 & 67.5 & 75.4 & 86.62 \\
\hline
\end{tabular}

Figure 1

A dam pilot magnetic concentration results.

Figure 2

B dam pilot magnetic concentration results.

Figure 3 D dam pilot magnetic concentration results.
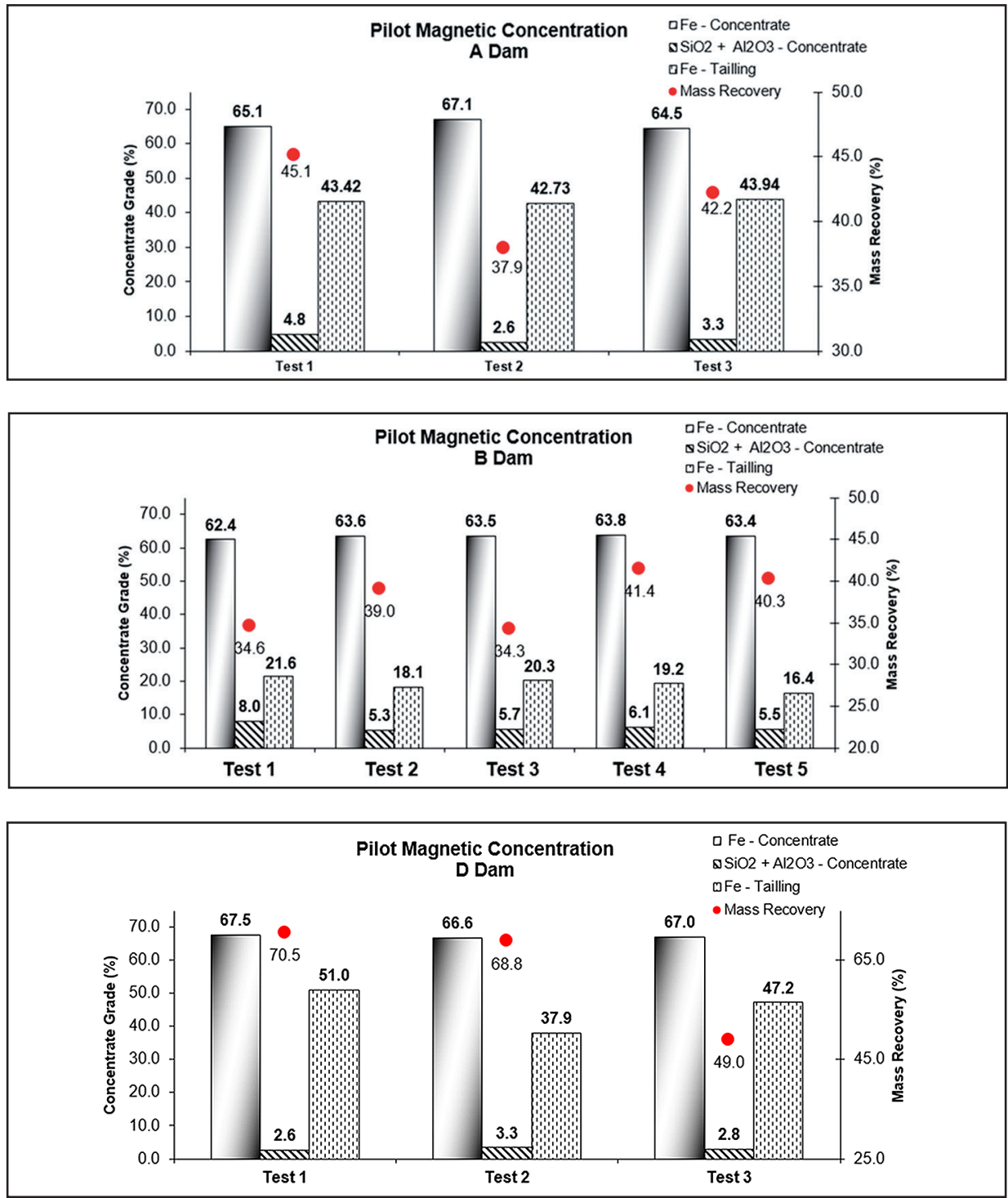
Figure 4 shows the particle size results for feed, concentrate, and tailings from pilot magnetic tests.

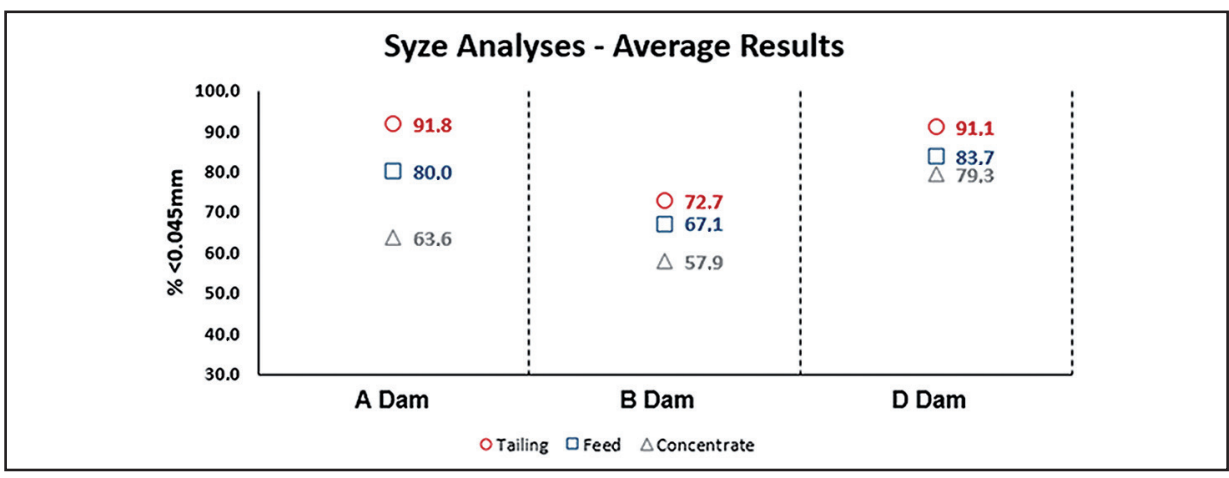

Reasonable results were achieved in the case of bench tests on the C dam's tailings samples, with a concentrate iron grade over $67 \%$ for all samples and an average recovery over $75 \%$ considering the three steps of magnetic concentration. A higher than $30 \%$ recovery in the first step under a $0.1 \mathrm{~T}$ magnetic field indicates the presence of ferromagnetic particles in the dam, so that a medium intensity magnetic concentration may be considered to process the tailings from this dam.

Regarding the A dam, bench tests obtained a concentrate iron grade between $63.6 \%$ and $66.7 \%$ with a mass recovery ranging from $49.0 \%$ to $64.0 \%$. Pilot tests corroborated the quality of concentrate obtained in the bench tests, with a concentrate iron grade in the $64.5 \%$ to $67.1 \%$ range.

\section{Conclusions}

Test results indicate the possibility of producing pellet feed fines at higher than $63 \%$ iron content using a magnetic concentration process for the four dams studied. The results were remarkably good for the C and D dams, in which the concentrate's iron content and mass recovery exceeded $66.5 \%$ and $67.0 \%$, respectively, in all tests carried out for both dams.
The pilot test mass recovery is significantly lower than in the bench test, ranging from $37.9 \%$ to $45.1 \%$. The reason for such a behavior may be a considerably higher amount of fines in this dam $(80.0 \%$ below $0.045 \mathrm{~mm})$, which is attracted by the magnetic field in the bench test, but is washed away by the water and incorporated into the tailings flow in the pilot test and industrial scale operation. The size results in Figure 4 show an increase in particles smaller than $0.045 \mathrm{~mm}$ in the tailings.

In the case of $\mathrm{C}$ dams, the bench test results indicate a concentrate iron grade from $64.3 \%$ to $65.5 \%$, with a mass recovery between $23.2 \%$ and $31.6 \%$. The limited mass recovery may be explained by the low feed iron grade and the $2.5-\mathrm{mm}$ plate box gap. In the pilot test, the gap
The iron content in the tailings outstripped $40 \%$ for the A and C dams, which may be explained by the fine particle size: $83.7 \%$ below $0.045 \mathrm{~mm}$ and $80.0 \%$ below $0.045 \mathrm{~mm}$, respectively. Magnetic separation efficiency is much lower in the case of such fine particles due to hydrodynamic drag.

Notwithstanding the test results,
Figure 4

Size analyses for pilot magnetic tests.

was reduced to $1.5 \mathrm{~mm}$ to improve mass recovery. The pilot test results show an improvement in mass recovery, with more than $34.0 \%$ in all tests. The concentrate iron grade was reduced to a range between $62.4 \%$ and $63.8 \%$.

The pilot test results for $\mathrm{D}$ dam are reasonable, with a concentrate iron grade ranging from $66.6 \%$ to $67.5 \%$ and mass recovery between $49.0 \%$ and $64.0 \%$. These results may be explained by the high iron grade of the samples, with average $58.0 \%$ Fe content. The same happened in the case of the A dam, where the high iron ore content in the tailings could be explained by the size range of the feed (83.7\% below $0.045 \mathrm{~mm}$ on average), which is carried by the water into the tailings flow.

\section{Acknowledgements}

iron recovery from the dams should consider a number of critical challenges, including particle size, material handling difficulties, and the presence of contaminants such as natural sediment, sand, and organic materials. These factors could cause instability in the beneficiation plant operations and reduce the mass recovery and quality of pellet feed produced.

We wish to thank Vale, especially the Technological Research Center teams, for all the support for this work.

\section{References}

FERRANTE, F. Estudo de viabilidade para recuperação de minério de ferro em rejeitos contidos em barragens. Ouro Preto: Escola de Minas, Universidade Federal de Ouro Preto, 2014. 86 p. (Dissertação de Mestrado).

PAULA, N. N. Estudos de correlação entre concentração magnética em escala de bancada, piloto e industrial. Belo Horizonte: Escola de Engenharia, Universidade Federal de Minas Gerais, 2014. 03 p. (Dissertação de Mestrado).

PENA, I., MARQUES, M. Redução do teor de ferro no rejeito da etapa de concentração do pellet feed. In: SIMPÓSIO BRASILEIRO DE MINÉRIO DE FERRO, 12. São Paulo: Associação Brasileira de Metalurgia e Materiais, 2011. p. 404-410. 
RIBEIRO, J. P., RIBEIRO, C. H. T. the NoBLOCK technology - a major breakthrough in wet high intensity magnetic separation (WHIMS). REM - International Engineering Journal, v. 68, n. 3, p. 361-366, Sep. 2015.

RIBEIRO, J. P., RIBEIRO, C. H. T., PINTO, P. F., ROCHA, R. B. The challenge to scavenge IRON from tailings produced by FLOTATION - A new approach: the super-WHIMS \& the bigFLUX magnetic matrix. REM - International Engineering Journal, v. 70, n. 3, p. 357-363, Jul. 2017.

SALES, C. G. Rotas de beneficiamento para recuperação de minerais portadores de ferro do underflow do espessador de lamas da usina de Brucutu. Belo Horizonte: Escola de Engenharia, Universidade Federal de Minas Gerais, 2012. 152 p. (Dissertação de Mestrado).

Received: 4 June 2018 - Accepted: 9 April 2019. 